\title{
Study on Knowledge Sharing Mechanism in Open Virtual Learning Communities
}

\author{
Wei Leng \\ Information Management Department \\ Central China Normal University \\ Wuhan 430079, China \\ E-mail: lengwei1987@hotmail.com
}

\begin{abstract}
Open-Virtual Learning Community (E-learning) which is Based on Web2.0 plays an important role in the course of study, in the basics of analyzing the basic content and features of the open-virtual learning community, a preliminary study of the knowledge sharing mechanism is made and some further optimization of the relevant mechanisms are shown.
\end{abstract}

Keywords: Web2.0, Open virtual learning community, Knowledge sharing

Networking Modern distance education has been surging up with the development trend of the network communication technology, and learning of students has been extended from the traditional classroom to informal learning outside the classroom, the concept of the Virtual Learning Community (E-Learning) has come into modern education, the open virtual-learning communities plays an increasingly important role in education. The development of Web 2.0 has built a new technology platform for our open virtual learning communities, enabling it to support the study of individual learning and collaborative learning, so that the open virtual learning community becomes an important part of our life. Knowledge-sharing has direct impact on the teaching quality and effectiveness of the virtual learning communities, so it is necessary to study on the knowledge-sharing model of open virtual learning community.

\section{The basic content of Open Virtual Learning Community}

\subsection{The meaning of Open Virtual Learning Community}

Open virtual community is one kind of virtual social patterns, which is established on the network and communication technology through networking and communications tools, it is composed by a variety of different types and individuals and it is created through education, research and other activities. Cross-learning, collaboration Learning and self-study-based approach are the mainly purposes of Open virtual community, enabling learners to acquire knowledge, enhance their understanding and skills in order to form a cross-regional autonomy. It is centered by learner and it pays attention to the timely feedback and learning, providing the interactive learning in line with personal needs and characteristics, with the support of interactive tools, students can express their view and communicate with others freely, thereby solve the problem, and achieve the learning goal. Open Virtual Learning Community provides a personalized learning environment, and it is a collective activity at the same time. There will be some study groups and project teams to discuss the area in the learning process. Learning and collaborative learning can be competed among the different kinds of learning groups, the learning atmosphere is free and open so it can provide a useful expansion for classroom education.

\subsection{The Construction and characteristics of Open Virtual Learning Community}

The openness of web2.0 mainly have the content opening, opening API as well as the source open software's development and the application. Users participate in the content on their own initiative in the foundation, found the related resources. At the same time, opening A P I might be possible to have more application fusions. According to the open source software development, many educators have done the massive work in the educational technique standard, the system construction as well as the interoperability aspect. In our Open Virtual Learning Community, the study resources may be quoted willfully, and form an open learning environment, thus truly realize a personalized, equal Open Virtual Learning Community. Web 2.0 has provided a simple, useful and function-formidable platform for the construction of Open Virtual Learning Community, and it provided individual knowledge management tool like BLOG, Podcast, the net for us to pick and so on, we might use each kind of these tools as well as those the web 2.0 platforms 
provided, so as to construct an Open Virtual Learning Community.

\section{Theoretical foundation of knowledge sharing in virtual learning community}

\subsection{The connotation of knowledge-sharing}

Knowledge sharing refers to the individual knowledge, and the organization knowledge is shared with other members in the organization through each sharing methods, simultaneously, it realizes organization's knowledge increment through the knowledge innovation. Therefore, the knowledge sharing should be understood from three level considerations : the knowledge sharing object — knowledge content, the knowledge sharing method — knowledge network, the conference and the team studies, the main body of knowledge sharing - team and organization.

Knowledge is one kind of scarce resource, it belongs to intangible asset of the knowledge main body, but this kind of property does not have the loss, namely, when a person provides the knowledge to another person, the providers will not therefore cause their own knowledge to reduce. If the web cam is regarded as the rational economic man, then it is hard to explain the knowledge exchange event in the Virtual community. The web cam not only provides the knowledge which individual has, but also needs to spend the time and the energy. From the perspective of economics, this kind of paying voluntarily cannot obtain the same value economical repayment immediately as the commodity exchange, it does not tally pursues the rational principle of the personal interest maximization. The society exchanging theory provides the rationale for this kind of knowledge sharing behavior. Among the human beings there are not only the economical exchange relations, but also the relations of society exchange. the theory representative of The society exchanges personage Browe (Blau) think that (4), the economical exchange stipulates the accurate quantity which is waiting for exchanging, but the principle of the society exchanges follows as "a person bestows favor for another person, although it will have one kind of general expectation from the regarding of some kind of future repayment, but its accurate nature beforehand has not made the specific stipulation", this kind of imaginary profit does not have accurate price and quantity, and bestowing favor will trust others to fulfill their duty.

\subsection{The connotation of knowledge-sharing in Open Virtual Learning Communities}

Because of the asymmetry of knowledge and difference of the knowledge structure, each learners have the knowledge blind spots, all people hope that they can obtain the knowledge which they need. Bieber et al believed that the Open Virtual Learning Community includes the explicit knowledge and the implicit knowledge, the former contains the study community documents, the discussing record, the conceptual model and the definition work class and so on, the latter originates from the study community member's cerebrum. Knowledge sharing refers to the different knowledge main body voluntary to transmit and share knowledge process mutually. the knowledge sharing of Open Virtual Learning Community includes two meanings, the first meaning is transmitting and exchanging knowledge mutually among the individual member in the Open Virtual Learning Community, for instance some members raise some questions, other member gives knowledge to solve the questions, or the individual members send the card in the community to pass on their own experiences and the skill knowledge on their own initiative; the second meaning refers to the Open Virtual Learning Community provides the knowledge as the knowledge main body to the member, the member offers the knowledge to the community, the community shares the knowledge mutually with the members, the concrete manifestation is collecting and reorganizing the knowledge record which the members remained while exchanging for the community, the member inquires some related knowledge on some subject from the community.

\section{The function of knowledge sharing in the open virtual learning community}

The open virtual learning community transforms individual implicit knowledge into the study community's explicit knowledge, then transforms community's explicit knowledge as individual implicit knowledge, so it has achieved the individual knowledge spiral loop. In this process, the explicit knowledge which in the community shared also to the individual implicit knowledge construction vital role. But through knowledge sharing, using the collective wisdom is helpful to enhance learner's strain, innovation ability, it can achieve the effect on the value multiplies through the knowledge share, the function of the knowledge sharing in open virtual learning community mainly displays in the following several aspects:

\section{1 constructing teaching interaction platform, providing resource sharing mechanism}

According to the knowledge sharing rationale, the open virtual learning community constructed a teaching interaction platform for the teaching, the open virtual learning community's knowledge sharing space and time did not limit, it has the cooperation study way characteristic which the convenience development computer network supported. Therefore, research development open virtual learning community knowledge sharing, may provide the resource sharing for the development education for all-around development, to raise student's innovation ability to provide the study space, enables the student not only to study the discipline knowledge, moreover can also master the knowledge acquisition the method, the way, the technology and the skill, focuses in raises ability which the student cooperation realizes as well as innovates. 


\subsection{Enhancing the knowledge acquisition, the ability on applying knowledge of community members}

The open virtual learning community can manage the knowledge resources and the knowledge operation process in the community, and promote the connection, the interaction and the conformity of knowledge resources, but open virtual learning community's knowledge sharing can be able to connect isolated islands to a knowledge system, it is advantageous to the community knowledge application and the innovation condition and the environment, thus enhances the learner knowledge acquisition, application knowledge, innovation knowledge ability.

\section{3 promote modern education's progress and knowledge innovation}

Based on the community agreement of virtual Learning, knowledge-sharing of communities is a system made up by link ways of knowledge flow among members of the community, in which the members can obtain knowledge, share and create it. The necessity of its existence is to make use of the creativity and potential, so as that explicit knowledge and tacit knowledge can convert to each other, in order to achieve knowledge innovation and modern education will be promoted at last.

\section{Constraints of Open Virtual Learning Communities}

\subsection{Unreasonable construction of knowledge sharing}

In open virtual learning communities, knowledge owned only by an individual is tacit while the knowledge exposed to each other is explicit. The knowledge obtained in informal studies is usually tacit, however the virtual learning communities lack the cultural atmosphere, learning environment and practical experience for the study of tacit knowledge, which obstructs the transfer, conversion and sharing of tacit knowledge. In the meantime, the construction of a knowledge-sharing model is also influenced when the knowledge-sharing platform is not focused, interactive, innovative and practical.

\subsection{Unsound Organizational system in Virtual learning communities}

Unsound organizational system in virtual learning communities is also one of the reasons why low level of knowledge-sharing forms.

\subsection{Limited technical support in knowledge-sharing}

Knowledge sharing technology supports limited virtual learning community. It is commonly used in the form of publish its own experience of knowledge by topic after members of the community log in. The system automatically records and provides attachment to guarantee members of the community can publish well. In order to encourage members of the community to attend activities in the community, the System automatically records the number which members published or browse files, in the same way to encourage appropriate on how much they participation. This kind of way in knowledge management played a role in the promotion of knowledge members of the community to create and share knowledge with each others, however, there is still some urgent problem in publishing and using of knowledge between members of the community, at first, with the passage of time, organization of knowledge's will be increasing, and the so called simple knowledge management

Creates obstacles for members of the community to get and use knowledge's. Second, members of the community can not be immediately noticed the new knowledge into the knowledge management system in time.

\subsection{Low sense of sharing of community members}

Knowledge management can make use of collective wisdom to enhance the organization's ability and creativity through knowledge-sharing, in which innovation and knowledge sharing is an important tool and a catalyst. Some members of the virtual learning community have no knowledge-sharing community awareness and knowledge of possession is exacted. If the members of the virtual learning community lack shared consciousness, in the study of knowledge cannot meet the demand for knowledge sharing, it may easily lead to the loss of community knowledge value.

\subsection{Limited ability to transform knowledge of members}

The process of cognitive knowledge is also the process of knowledge conversion, which includes of socialization, externalization, combination and internalization. These progresses are interdependent and interrelated. If the support for knowledge conversion of the virtual learning community just stay at the stage that at which the support is independent, it will lead that knowledge increase grows slowly while the resources of community are increasing, which will confuse the scholars. Lacking of ability of knowledge conversion will also affect the knowledge-sharing.

\section{The optimization of knowledge-sharing model in Open Virtual Learning Community}

\subsection{The promotion of the technology in building virtual learning community}

It is beneficial for the activities of knowledge sharing among the members in the virtual learning community to promote the technology in building virtual learning community. And the key element to success of knowledge sharing is to take the technology means which are advanced, suitable and friendly to the member in the community. 
5.1.1 To meet the personalized need. Information technology used in knowledge sharing should be satisfied to the various and active demands of the members

\subsection{To improve easy-using and easy-learning of the technology}

Because of the differences among the member's quality, the information technology put to use in constructing the virtual learning community should be easily to understand and accept. The more acceptable technology is in used, the quicker speed the members comminute with each other, and the more easily the knowledge sharing among the members in the community can be accomplished.

\subsubsection{To develop characteristic software for stimulating the members doing more activities in knowledge sharing}

For example, virtual community can offer a chatting room or a platform for interactive activities to encourage more discussion, which can realize the knowledge sharing among the members.

\subsubsection{To reduce the restrictions of management among the members}

It is necessary to cut down the restrictions on the upload, download and sending files in the members on the condition that it won't influence the safety of the community. Hitherto, many communities take a lot of restrictions on transferring the files considering the safety of the sites, which have bad effects on the knowledge sharing activities. If it is cut down, the quantity and quality of the transferring files among the members will improved, and also the entire level for the knowledge sharing.

\subsubsection{To satisfied the need of the members in techno ledge}

The hardware and software should make sure the ability of transmission and management of information that can approach the members' demand. It's essential to improve the skills of the members of the community, to achieve the perfect match between human and computers, and to make a balance in the skills of members..

\subsection{Establishments of protection mechanisms in knowledge-sharing}

Virtual Learning Community norms of the characteristics of the virtual community has decided to study its binding members of the community weaker than the reality, virtual learning communities more vulnerable members of the flow, which restricts the sharing of knowledge of continuity and stability to the management of more operations Difficulties and thus, a virtual community of knowledge-sharing communities to the main members of the common needs of the inner sense of identity, as well as members of the virtual learning community has internalized the self-discipline and moral principles. This article will define the virtual community regulate as a virtual community on the basis of culture, the rules of the community, reflected in Etiquette comprehensive. Virtual Learning Community norms are: (1) physical standards -virtual learning community managers to develop written rules of social systems (such as community law); (2) invisible norms of virtual learning communities in the process of development gradually the formation of the unique cultural and community-based members of the default of the norms of decency. Virtual Learning Community norms of fairness, cooperation, dedication, innovation and bound by the spirit of each member of the virtual community to share knowledge, in its guarantee, the members of the community in the knowledge-sharing in compliance with certain rules, is more conducive to improving the efficiency of the knowledge-sharing.

\subsection{Raise awareness of members in of the team}

The difference among On-line learning communities, other online learning communities and other web-based learning is platform the system design into a "collective" concept, the learners will not feel "lonely", there is a sense of belonging, the use of "community sentiment" To maintain relatively stable number of study groups, to allow virtual communities really become members of the community attached to the common "spiritual home." First of all, the system will be different according to the learner's interest in learning the organization into a learning organization; the group is full of internal communication and collaboration, team cohesion to the system used to inspire students with appropriate "incentives" to encourage students to play the team spirit of collaboration, to accomplish the common goal of the study. E-learning students in the whole process will be to urge the organization to learn and help. Learners can also be classified according to different groups into a learning team, so that all members of the team through communication and mutual support, by cooperation study, students completed their study goals, then achieve the common goal in the final team so that achieve virtual learning community to share knowledge. Teamwork, knowledge-sharing on individual learners to study the role of support act is enormous, which allows learners have a strong sense of mission and responsibility, exercise personal creativity and self-learners beyond the capacity.

\subsection{Broaden the knowledge-sharing channels}

Those who construct the virtual learning community should try to broaden the knowledge-sharing channels by ways such as on-line discussion forum, blog, Wiki, e-mail, information stations, to make the knowledge-sharing available. But one must firstly master the basic knowledge and basic skills to access on-line resources, know how to operate the browser, reader, player, search engines, download tools. Learners positively take part in a wide range of subject, and the 
skills of querying and browsing the information are improved, but also skills of exchanging the information are enhanced.

\section{References}

Luo, Zhiyong. (2003). Knowledge-sharing mechanism . Beijing Library Press.

Peter Blau. (1988). Social life and the Exchange of Power. Beijing: China Press.

Cao, Zaihui, \& Yu, Dongxian. (2007). Theory of Knowledge Management for the Construction of Virtual Learning Communities Revelation. Modern Distance Education, 6.

Huang, Yan. (2006). A Network of Virtual Learning Environment to Explore the Community. Ningbo Journal of Radio and Television University.

Ye, Haizhi, Wang, Fuqiang \& Xin, Shanghong. (2008). Study on Virtual Learning Communities and Effective Access to the Contents of Learning. China Education Information, 7.

Wang, Lu, Yang, Hui, \& Dong, Le. (2001). E-learning Environment-Virtual Learning Community Research and Application. Journal of Tianjin TV, 9.

$\mathrm{Xu}$, Xiaolong and so on. (2007). Virtual Community of Knowledge-sharing Mechanism. Dialectics of Nature, 8. 